\title{
The Patient Protection and Affordable Care Act: impact on care to patients with paediatric and congenital cardiac disease
}

\author{
Michael G. Gaies, ${ }^{1}$ Jeffrey P. Jacobs, ${ }^{2}$ Timothy B. Cotts, ${ }^{1}$ Matthew M. Davis ${ }^{3}$ \\ ${ }^{1}$ Department of Pediatrics and Communicable Diseases, University of Michigan, C.S. Mott Children's Hospital, Ann \\ Arbor, Michigan; ${ }^{2}$ Department of Surgery, University of South Florida, Johns Hopkins Children's Heart Surgery, \\ All Children's Hospital, St. Petersburg, Florida; ${ }^{3}$ Department of Pediatrics and Communicable Diseases, Gerald R. Ford \\ School of Public Policy, Division of General Medicine, Child Health Evaluation and Research (CHEAR) Unit, \\ Institute for Healthcare Policy and Innovation, University of Michigan, Ann Arbor, Michigan, United States of America
}

Keywords: Policy; pediatric; congenital; cardiac; cardiac surgery

Received: 24 July 2013; Accepted: 4 August 2013; First published online: 10 September 2013

$\mathrm{T}$ he Patient Protection and Affordable Care Act, signed into law by President Barack Obama in 2010 and frequently referred to by the acronym "ACA", focuses predominantly on expanding health insurance coverage for adults. The ACA holds similar promise for improving care to children and young adults with paediatric and congenital cardiac disease. In fact, the ACA includes a provision entitled the "Congenital Heart Futures Act" that specifically speaks to research and clinical advances for individuals with paediatric and congenital cardiovascular conditions.

To help broaden awareness in the cardiology care community about the ACA and its implications for patients with congenital heart disease, including the clinicians and researchers who care for them, we describe here the potential positive effects from the ACA for patients with paediatric and congenital cardiovascular disease, important questions that remain, and future areas of research to assess the overall impact on this population. Specifically, we introduce the Congenital Heart Futures Act and then analyse the potential impact of the ACA on the specialties of paediatric cardiology and paediatric cardiac surgery focusing on three key domains of the ACA highlighted by the American Academy of Pediatrics: access, benefits, and coverage. ${ }^{1}$

Correspondence to: M. G. Gaies, MD, MPH, University of Michigan Congenital Heart Center, C.S. Mott Children's Hospital, 1540 East Medical Center, Ann Arbor, MI 48109-4204, United States of America. Tel: + 1 734936-3770; Fax: +1 734-936-9470; E-mail: mgaies@med.umich.edu

\section{The Congenital Heart Futures Act}

A unique provision in the ACA known as the Congenital Heart Futures Act (S.621 IS) provides several key policy initiatives for the paediatric and congenital cardiac community. ${ }^{2,3}$ This bill amends Title III of the Public Health Service Act (42 U.S.C. 241 et seq.) and directs the US Secretary of Health and Human Services, working with the Centers for Disease Control and Prevention, to raise public awareness and provide funding for research in congenital heart disease. The act calls for development of a congenital heart disease registry to track incidence and prevalence, risk factors, and outcomes for patients, including longitudinal data into adulthood. A registry with all of these features does not currently exist in the United States. The Public Health Service Act is further amended to contain language regarding the development of a multidisciplinary congenital heart disease advisory board that will report to the Secretary of Health and Human Services and Centers for Disease Control and Prevention on the use of data from the proposed registry.

These key components of the Congenital Heart Futures Act are particularly important in a rare disease field, where national and multi-institutional databases provide the best opportunity to perform robust science with sufficient power to make clinical and policy recommendations. ${ }^{4,5}$ Although it remains to be seen how each of these initiatives will be operationalised, and to what degree these initiatives might increase congenital cardiac disease 
research, there is no doubt that the Congenital Heart Futures Act has great potential to enrich the infrastructure for discovery in paediatric and congenital cardiac disease science and to promote advocacy for children and adults living with these diseases. In December 2011, \$2 million was appropriated to the Centers for Disease Control and Prevention to increase surveillance efforts for congenital heart disease. To ensure future funding of this uniquely targeted initiative, clinicians, researchers, and patient advocates will need to continue to communicate to lawmakers the likely improvements in processes of care and health outcomes that may result from activities under the Congenital Heart Futures Act.

\section{Impact of the ACA on access}

Training an adequate number of sub-specialists to care for patients with paediatric and congenital cardiovascular disease is a major component of providing quality care in the future to this growing population of patients. Fortunately, improving access to paediatric sub-speciality care is a hallmark objective of the ACA. The paediatric sub-speciality physician workforce is expected to be bolstered by the new loan repayment programme amended to Title VII of the Public Health Service Act. ${ }^{6}$ The pool of potential paediatric cardiology trainees is also likely to increase as a result of graduate medical education reform that appropriates greater resources for paediatric training programmes, and thus generates more positions at institutions providing sub-speciality care for children. ${ }^{7}$ Ongoing research will be necessary to determine the extent to which such provisions lead to an increase in the paediatric cardiology workforce compared with paediatric primary care and other sub-specialities.

A key aspect of the emphasis in the ACA on paediatric sub-speciality training is the goal of improving access to specialised outpatient cardiology care for children and adults with congenital heart disease in rural and underserved regions. Preliminary work ${ }^{8}$ suggests the presence of regional variation around gaps in care for these patients, but the underlying reasons for this regional variation are incompletely understood. Future research is necessary to determine whether lack of access to care contributes this variation, whether increasing subspecialists in currently underserved areas reduces the variation, and whether the ACA's policies improve access to care in these areas.

Related to these workforce issues, another important question is whether adult congenital heart disease, a clinical discipline newly recognised by the American Board of Medical Specialties, will be included as a paediatric sub-speciality in ACA-sponsored loan repayment programmes. Considering the growth of the adult congenital heart disease population? (see below), efforts to increase the number of specialists trained to meet the needs of this unique population seem warranted. Incentivising the choice to specialise in adult congenital heart disease may raise interest among physicians primarily trained in internal medicine who would otherwise not be eligible for loan repayment. This strategy could potentially shift the mix of physicians entering the field away from those who have completed a paediatrics residency; however, as both internal medicine and paediatrics residency programmes are viable entry points into the adult congenital heart disease speciality, this shift is likely not a troublesome issue.

An additional area of concern regarding access in the field of complex congenital cardiovascular disease, where complex inpatient and ambulatory care is frequently provided at academic medical centres that serve as disproportionate share hospitals, is related to the reduction of Medicaid disproportionate share hospital payments to states specified in the ACA. ${ }^{10}$ Cuts in Medicaid disproportionate share hospital payments by 2019 are expected to represent $\sim 50 \%$ of the disproportionate share hospital funds originally projected to go to these hospitals. ${ }^{11}$ The premise for reducing Medicaid disproportionate share hospital payments over time in the ACA era is that Medicaid expansion financed by the ACA will decrease the burden on disproportionate share hospital institutions that currently provide "safetynet" care to disproportionate numbers of uninsured and underinsured patients. However, in states that do not implement Medicaid expansion, disproportionate share hospital institutions may see their pool of revenue diminish markedly, without a concomitant decrease in the uninsured population. ${ }^{12}$ These hospitals may face the difficult decision of having to reduce care to the population with congenital heart disease, if there is no alternative supplement for the unreimbursed costs incurred by treating poor and uninsured patients.

The financial health of prominent urban paediatric cardiac centres acting as safety-net hospitals, particularly in states that do not plan to expand Medicaid coverage $^{13}$ - for example, All Children's Hospital Johns Hopkins Medicine, Saint Petersburg, FL; Texas Children's Hospital in Houston, TX; Medical University of South Carolina Children's Hospital, Charleston, SC; Children's Hospital of Philadelphia, Philadelphia, PA - will be important to follow as the ACA is implemented and disproportionate share hospital payments are reduced. The financial squeeze of reducing disproportionate share hospital payments 
and limiting Medicaid expansion is analogous to treating post-operative haemorrhage without fresh frozen plasma or platelets. Members of the paediatric cardiology community may need to prepare to advocate for special exceptions to disproportionate share hospital reductions for safety-net institutions where highly specialised paediatric care is provided.

\section{Impact of the ACA on health benefits}

Children with acute and chronic healthcare needs resulting from cardiovascular disorders will be assured of comprehensive benefits under Medicaid and newly established health insurance plans offered and subsidised through state exchanges - that is, new state-based markets for private health plans. These benefits include hospitalisation and ambulatory services, chronic disease management, prescription drugs, and rehabilitative devices. ${ }^{1}$ This set of services is crucial for patients with critical congenital heart disease and those requiring cardiac surgery.

In addition, the inclusion of broad benefits for basic primary care services in plans under the ACA will allow children with chronic conditions to obtain the basic preventive and acute care interventions that protect against minor illnesses and conditions that might have a disproportionate impact on children with complex cardiovascular disease. Specifically, the ACA codifies the Medicaid Equal Access Clause, which requires states to provide sufficient payments to paediatricians and other healthcare providers to administer care equivalent to that offered to the privately insured population. The new law reaffirms the intent for provision of standard services to lowincome children with cardiac conditions and other chronic illnesses.

\section{Impact of the ACA on coverage}

Expanding insurance coverage for children and young adults with paediatric and congenital cardiac disease is likely to have a profound effect on the health of this population. Beginning with Medicaid expansion, ${ }^{14}$ continuing with SCHIP in 1997 and extending with CHIP reauthorisation in $2009,{ }^{15}$ the proportion of US children with health insurance is at an all-time high.

However, young adults with paediatric and congenital cardiac disease stand to benefit greatly from the ACA's coverage increases. Adults with congenital heart disease symbolise the success of our field over the previous four decades, as more adults are now living with congenital cardiac disease than

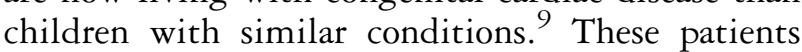
face marked challenges in transition of care as they grow to adulthood, and the literature suggests that a large proportion do not receive any care at all for extended periods, much less from specialists best trained to meet their needs. ${ }^{8}$ Improved insurance coverage during this time of transition holds great promise to improve care for the adult congenital heart disease population.

Inclusion of dependents until the age of 26 years on parental plans under the ACA will start to close the existing gaps in coverage. ${ }^{16}$ Guaranteed insurance coverage for patients with pre-existing conditions $^{16}$ relieves concerns for this patient population as well. Previous work has suggested that lack of private insurance may influence the likelihood of seeking care in the emergency department and hospital admission rates for patients with adult congenital heart disease who are older than 17 years of age. ${ }^{17}$ Presumably, young adults with adult congenital heart disease who retain dependent coverage until the age of 26 years will be more likely to receive ongoing care from specialists and will have fewer exacerbations of underlying disease that require these episodes of acute care.

One final aspect of the ACA coverage provisions has important implications for the adult congenital heart disease community. Bans on lifetime benefits limits ${ }^{16}$ for approved plans will relieve concerns for those families with children who have the most complex cardiac conditions. For example, a patient with hypoplastic left heart syndrome requires at least three surgeries in the first few years of life. The initial palliation (Norwood procedure) carries an average cost of nearly $\$ 215,000$, and the subsequent second and third stage average $\sim \$ 82,000$ and $\$ 79,000$, respectively. ${ }^{18}$ Many of these patients are likely to require complex care in young adulthood as well, including a fair proportion of mechanical assist devices and cardiac transplantation. Clearly, the high costs associated with similar conditions represent what might be an unmanageable burden without the enactment of the ACA.

\section{Conclusion}

The ACA offers potential for major improvements in the delivery of healthcare to children and adults with paediatric and congenital heart disease. The community of clinicians and scientists who care for this unique patient population must seize the opportunities provided by the law to translate policy into better outcomes for our patients. We should participate in ongoing efforts to study the effects of the ACA on issues such as the speciality workforce, access to care, and the quality of care received. Finally, though the legislation holds significant promise for our patients, continued advocacy efforts by clinicians and scientists will likely be necessary to 
refine and improve certain policy aspects and the implementation of the law.

\section{Financial Support}

Research informing this article was conducted by the authors with internal funds. Dr Davis is funded in part by the Michigan Department of Community Health, as the state's chief medical executive. Views expressed here are those of the authors and do not necessarily represent the views of any funders, including the Michigan Department of Community Health.

\section{References}

1. Health Reform and the AAP: What the New Law Means for Children and Pediatricians. Retrieved December 13, 2012, from www.aap.org

2. S. 621-111th Congress: Congenital Heart Futures Act, 2009. Retrieved April 16, 2013, from http:/www.govtrack.us/congress/ bills/111/s621.

3. Patient Protection and Affordable Care Act. Public Law 111-148, 42 USC 256a-1, § 10411, March 31, 2010.

4. Jacobs JP. Supplement to Cardiology in the Young: databases and the assessment of complications associated with the treatment of patients with congenital cardiac disease, prepared by: the multi-societal database committee for pediatric and congenital heart disease. Cardiol Young 2008; 18 (Suppl S2): 1-530.

5. Jacobs JP, Maruszewski B, Kurosawa H, et al. Congenital heart surgery databases around the world: do we need a global database? Semin Thorac Cardiovasc Surg Pediatr Card Surg Annu 2010; 13: $3-19$.
6. Patient Protection and Affordable Care Act. Public Law 111-148, 42 USC 256a-1, § 5203, March 31, 2010.

7. Patient Protection and Affordable Care Act. Public Law 111-148, 42 USC 256a-1, § 5301, March 31, 2010.

8. Gurvitz M, Valete AM, Broberg C, et al. Prevalence and predictors of gaps in care among adult congenital heart disease patients: HEART-ACHD (The Health, Education, and Access Research Trial). J Am Coll Cardiol 2013; 61: 2180-2184.

9. Marelli AJ, Mackie AS, Ionescu-Ittu R, Rahme E, Pilote L. Congenital heart disease in the general population: changing prevalence and age distribution. Circulation 2007; 115: 163-178.

10. Patient Protection and Affordable Care Act. Public Law 111-148, 42 USC 256a-1, § 2551, March 31, 2010.

11. See Memorandum from Richard S. Foster, Chief Actuary, Ctr for Medicare \& Medicaid Services. Retrieved May 30, 2013, from https://www.cms.gov/Research-Statistics-Data-and-Systems/ Research/ActuarialStudies/Downloads/PPACA_2010-04-22.pdf.

12. Graves JA. Medicaid expansion opt-outs and uncompensated care. N Engl J Med 2012; 367: 2365-2367.

13. State Decisions on Health Insurance Exchanges and the Medicaid Expansion. Retrieved May 30, 2013, from kff.org.

14. Patient Protection and Affordable Care Act. Public Law 111-148, 42 USC 256a-1, § 2001, March 31, 2010.

15. Patient Protection and Affordable Care Act. Public Law 111-148, 42 USC 256a-1, § 2101, March 31, 2010.

16. Patient Protection and Affordable Care Act. Public Law 111-148, 42 USC 256a-1, § 1001, March 31, 2010.

17. Gurvitz MZ, Inkelas M, Lee M, Stout K, Escarce J, Chang RK. Changes in hospitalization patterns among patients with congenital heart disease during the transition from adolescence to adulthood. J Am Coll Cardiol 2007; 49: 875-882.

18. Dean PN, Hillman DG, McHugh KE, Gutgesell HP. Inpatient costs and charges for surgical treatment of hypoplastic left heart syndrome. Pediatrics 2011; 128: e1181-e1186. 